\title{
Carboboration of isocyanates with tris(pentafluorophenyl)borane and evidence for dissociative FLP chemistry of an acid-base pair
}

Received 00th January 20xx, Accepted 00th January 20xx

DOI: $10.1039 / \times 0 \times x 00000 x$

\author{
Meera Mehta, ${ }^{* a}$ and Jose M. Goicoechea*a
}

We report on the reactivity of isocyanates towards tris(pentafluorophenyl)borane which was found to result in the 1,2-carboboration of the isocyanate $\mathrm{C}=0$ bond. The resulting sixmembered heterocyclic compounds can be rationalized as adducts of imino-boranes with isocyanates and react accordingly, allowing for the dissociative displacement of the trapped isocyanate moiety in a series of exchange reactions. Related carboelementation reactions with the heavier group 13 analogues, $\mathrm{Al}\left(\mathrm{C}_{6} \mathrm{~F}_{5}\right)_{3}$ and $\mathrm{Ga}\left(\mathrm{C}_{6} \mathrm{~F}_{5}\right)_{3}$, result in a dimerization of the carboboratation products to afford eight-membered heterocycles.

Tris(pentafluorophenyl)borane $\left[\mathrm{B}\left(\mathrm{C}_{6} \mathrm{~F}_{5}\right)_{3} ; \mathrm{BCF}\right]$ is a strong Lewis acid which was first synthesized in the 1960s and has, more recently, become a ubiquitous component of frustrated Lewis pair systems (FLPs). ${ }^{1-3}$ BCF, and related boranes featuring pentafluorophenyl substituents, are attractive Lewis acids as they are highly electrophilic, ${ }^{4}$ yet stable with regard to hydrolytic cleavage of the $B-C$ bonds. However, like many other boranes, the $\mathrm{B}-\mathrm{C}$ bonds in this species are not chemically inert, and have been shown to react in a number of carboboration processes adding across unsaturated elementelement bonds. Of these carboboration reactions, the most well-studied, is 1,1-carboboration of alkynes, ${ }^{5}$ which has a historic precedent in the Wrackmeyer reaction. ${ }^{6}$ Such carboboration reactions are an attractive synthetic route to substituted alkenes, provided that the regio- and stereoselectivity of this transformation can be controlled. By contrast, 1,2-carboboration reactions are much rarer, and limited to metal-catalyzed carboboration reactions. ${ }^{7}$ Metalfree 1,2-carboboration reactions of alkynes are, to date, the exclusive purview of borocations, as recently demonstrated by Ingleson and Bourissou. ${ }^{8,9}$ Melen, Hansmann and co-workers recently reported on the 1,2-carboboration of allenyl ketones and esters in the presence of BCF. In the case of allenyl ketones the products were cyclic dihydroxyborinines. ${ }^{10}$ These

\footnotetext{
a. Department of Chemistry, University of Oxford, Chemistry Research Laboratory, 12 Mansfield Road, Oxford, OX1 3TA, U.K.

E-mail:meera.mehta@chem.ox.ac.uk; jose.goicoechea@chem.ox.ac.uk

Electronic Supplementary Information (ESI) available: Experimental and analytical data for all compounds. See DOI: 10.1039/x0xx00000x
}

studies prompted us to explore the reactivity of BCF towards other heteroallenes, specifically isocyanates.

The reaction of $B C F$ with a stoichiometric excess of isocyanates $(\mathrm{O}=\mathrm{C}=\mathrm{N}-\mathrm{R}$; where $\mathrm{R}=\mathrm{Ph}, \mathrm{Cy}$, allyl) affords cyclic six-membered compounds $\mathbf{1 a}, \mathbf{1 b}$ and $\mathbf{1 c}$ (where $\mathrm{R}=\mathrm{Ph}, \mathrm{Cy}$, allyl, respectively) as pictured in Scheme 1 . The reaction involves the 1,2-carboboration of one equivalent of the isocyanate to afford an unobserved intermediate featuring $\mathrm{B}-$ $\mathrm{O}$ and $\mathrm{C}-\mathrm{C}_{6} \mathrm{~F}_{5}$ bonds. This reaction is reminiscent of a related transformation previously reported by Cowley and co-workers in which dicyclohexyl carbodiimide was shown to react with $\mathrm{PhBCl}_{2}$ resulting in the insertion of the heterocumulene into the $\mathrm{B}-\mathrm{C}$ bond of the borane to afford the benzamidinate compound $\left[\mathrm{PhC}(\mathrm{CyN})_{2}\right] \mathrm{BCl}_{2} \cdot{ }^{11}$ More recently, analogous reactivity has been observed with $\mathrm{BCF}$ and carbodiimides. ${ }^{12}$

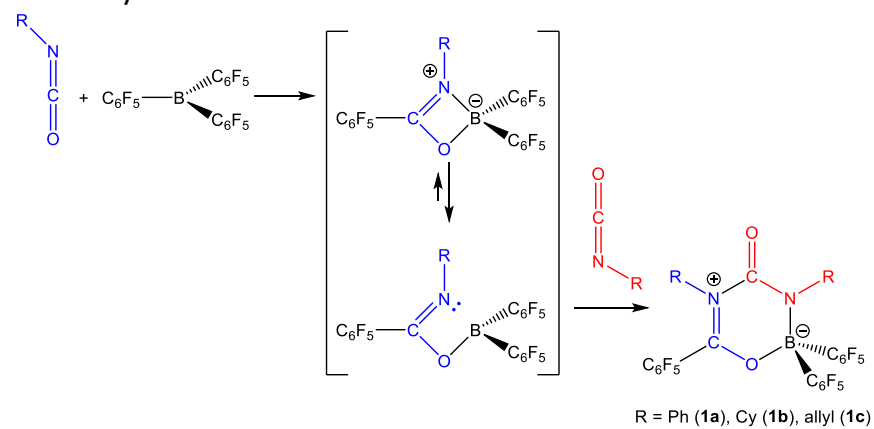

Scheme 1. Carboboration of isocyanates by $B\left(C_{6} F_{5}\right)_{3}$ to afford 1a-1c.

This postulated imino-borane intermediate can be rationalised as a frustrated Lewis pair (FLP) which goes on to react with a further equivalent of isocyanate to afford the final six-membered ring. Comparable reactivity has been reported for boron amidinates such as $\mathrm{HC}(\mathrm{RN})_{2} \mathrm{~B}\left(\mathrm{C}_{6} \mathrm{~F}_{5}\right)_{2}\left(\mathrm{R}={ }^{i} \mathrm{Pr},{ }^{t} \mathrm{Bu}\right)$ with heteroallenes such as $\mathrm{CO}_{2}$ and carbodiimides. ${ }^{13}$ Trapping of isocyanates with intramolecular FLPs has also been reported by Erker and co-workers, ${ }^{14}$ while Martin has shown that isocyanates can insert into antiaromatic boroles. ${ }^{15}$ It is worth noting that a six-membered carboboration product related to 1a-1c, resulting from the reaction of $\mathrm{FcB}\left(\mathrm{C}_{6} \mathrm{~F}_{5}\right)_{2}\left[\mathrm{Fc}=\mathrm{Fe}\left(\eta^{5}-\right.\right.$ $\left.\left.\mathrm{C}_{5} \mathrm{H}_{5}\right)\left(\eta^{5}-\mathrm{C}_{5} \mathrm{H}_{4}\right)\right]$ with cyclohexyl isocyanate, has been previously reported by Aldridge, ${ }^{16}$ although the subsequent chemistry of 
this compound has not been investigated. To the best of our knowledge, in all of the aforementioned examples there is no evidence for the reversibility of such insertion reactions.

The NMR spectra of $\mathbf{1 a}, \mathbf{1} \mathbf{b}$ and $\mathbf{1 c}$ are consistent with the presence of two distinct $\mathrm{C}_{6} \mathrm{~F}_{5}$ environments in a 2:1 ratio as evidenced by their ${ }^{19} \mathrm{~F}$ NMR spectra [e.g. for 1a: $-135.0 /-139.1$ ppm (ortho), -142.8/-153.2 ppm (para) and -157.4/-162.5 ppm (meta)]. The ${ }^{11} \mathrm{~B}$ NMR spectra reveal a sharpened singlet resonance consistent with a pseudo-tetrahedral borate $(4.0$ ppm for 1a).

Crystals of $\mathbf{1 a}, \mathbf{1 b}$ and $\mathbf{1 c}$ could be grown from concentrated hexane or toluene solutions, allowing for the isolation of the resulting products in good yields (1a: $68 \%$; $1 \mathbf{b}$ : 70\%; 1c: $63 \%$ ). Single crystal X-ray analysis of all three samples revealed comparable bond metric parameters (consequently only the structure of $\mathbf{1 a}$ will be discussed in detail). The structure of $1 \mathbf{1 a}$ is based on a non-planar six-membered heterocycle featuring a pendant carbonyl functionality (mean deviation from planarity $=0.14 \AA$ A . Analysis of the bond lengths within the heterocycle suggest that there is some degree of delocalized $\pi$-character within the carboborated $\mathrm{N} 2-\mathrm{C} 2-\mathrm{O} 2$ unit $(\mathrm{N} 2-\mathrm{C} 2=1.323(2), \mathrm{C} 2-\mathrm{O} 2=1.271(2) \AA)$ and within the amido moiety defined by N1-C1-O1 (N1-C1 = 1.336(2) $\AA$, C1$\mathrm{O} 1=1.205(2) \AA ̊)$. The relatively long N2-C1 distance (1.485(2) $\AA)$, on the other hand, suggests no significant delocalization between these two fragments. This suggests that 1a can be rationalized as a Lewis acid-base adduct of an isocyanate (that defined by 01-C1-N1) with an imino-borane (defined by N2C2-O2-B1). Subsequent reactivity studies reveal that despite forming a strong adduct, dissociation of the isocyanate moiety is possible. It is worth noting that comparable bond distances have been previously reported for the insertion product of the boron amidinate $\mathrm{HC}\left({ }^{i} \mathrm{PrN}\right)_{2} \mathrm{~B}\left(\mathrm{C}_{6} \mathrm{~F}_{5}\right)_{2}$ with carbodiimides such as ${ }^{i} \operatorname{PrNCN}{ }^{i} \operatorname{Pr}(\mathrm{N}-\mathrm{C}: 1.462(2) \AA ̊) .{ }^{13}$

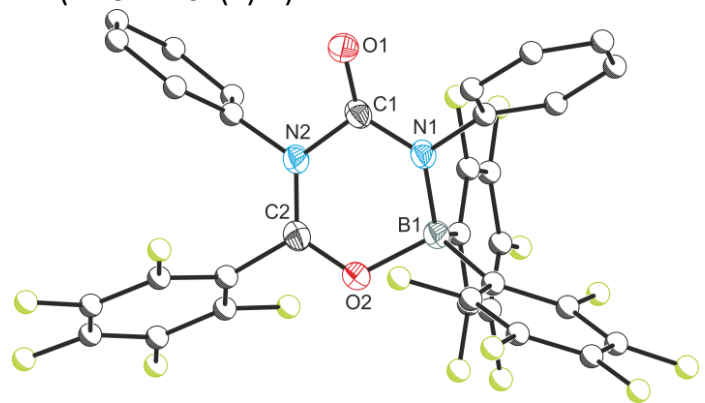

Figure 1. Molecular structure of 1a. Anisotropic displacement ellipsoids set at 50\% probability. Hydrogen atoms have been omitted for clarity. Atoms of the Ph and C6F5 moieties are pictured as spheres of arbitrary radius. Selected interatomic distances $[\AA]$ and angles [ ${ }^{\circ}$ ]: B1-N1 1.539(2); N1-C1 1.336(2), C1-O1 1.205(2), C1-N2 1.485(2), N2C2 1.323(2), C2-O2 1.271(2), O2-B1 1.563(2); B1-N1-C1 122.64(11); N1-C1-O1 129.77(12), N1-C1-N2 113.38(11), C1-N2-C2 122.64(11), N2-C2-O2 122.82(12), C2-O2B1 117.99(10).

Reaction of $\mathbf{1 a}$ or $\mathbf{1 b}$ with an excess of a different isocyanate was found to give rise to novel ring systems in which the "trapped" isocyanate moiety (displayed in red in Scheme 2) is displaced to afford a novel scrambled compound where $\mathrm{R} \neq \mathrm{R}^{\prime}$. For example, if $\mathbf{1 a}$, in which both nitrogen atom substituents are phenyl groups, is reacted with an excess of CyNCO, a novel scrambled product $\mathbf{2}$, is formed in which $\mathrm{R}=\mathrm{Ph}$ and $R^{\prime}=C y$. This transformation allows for the synthesis of cyclic products with different exo-functional groups associated with the nitrogen atoms. The ${ }^{1} \mathrm{H}$ NMR spectrum of this reaction mixture indicates that there is an equilibrium at play in which both $\mathbf{1 a}$ and $\mathbf{2}$ are present along with both isocyanates RNCO $(R=P h, C y)$. The equilibrium can be pushed to afford clean conversion to $\mathbf{2}$ by addition of a large excess of CyNCO. This equilibrium was further confirmed by reaction of a compositionally pure sample of $\mathbf{2}$ with PhNCO to regenerate 1a. It is worth noting that these reactions require heating (typically to $110{ }^{\circ} \mathrm{C}$ ) to reach equilibrium over the course of several hours, however if the reactions are carried out at room temperature the mixture also ultimately equilibrates, albeit over the course of several days. For any given mixture of $\mathbf{1 a}$ and 2, the final position of the equilibrium is independent of temperature (vide infra) and is solely influenced by the initial concentration of cyclohexyl isocyanate). The substituents of the isocyanates have an influence on the ratio of products on reaching equilibrium, with aromatic functionalities being favoured over aliphatic ones. Equimolar reactions of $\mathbf{1 b}$ with phenyl isocyanate, $p$-chlorophenyl isocyanate, $p$-bromophenyl isocyanate, and $p$-methoxy isocyanate resulted in near quantitative conversion to $\mathbf{3 a}, \mathbf{3 d}, \mathbf{3 e}$, and $\mathbf{3 g}$. Whereas, the related reaction with $p$-nitrophenyl isocyanate resulted in $25 \%$ conversion to $\mathbf{3 f}$.

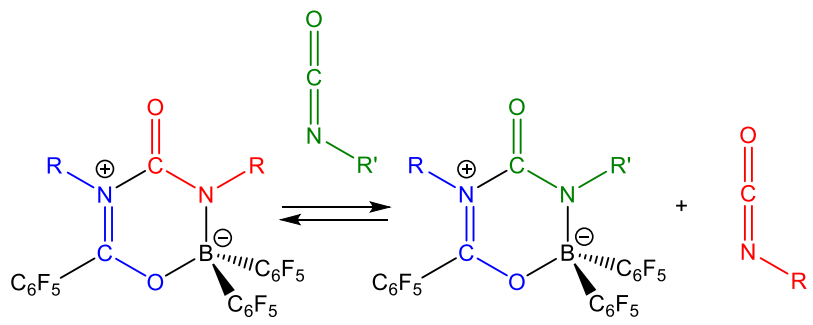

$$
\begin{aligned}
& R=P h, R^{\prime}=C y(2) \\
& R=C y, R^{\prime}=P h(3 a) \\
& R=C y, R^{\prime}=\text { allyl (3b) } \\
& R=C y, R^{\prime}=B z(3 c)
\end{aligned}
$$$$
\mathrm{R}=\mathrm{Cy}, \mathrm{R}^{\prime}=\text { para }-\mathrm{C}_{6} \mathrm{H}_{4} \mathrm{Cl}(\mathbf{3 d})
$$

$\mathrm{R}=\mathrm{Cy}, \mathrm{R}^{\prime}=$ para $-\mathrm{C}_{6} \mathrm{H}_{4} \mathrm{Br}(\mathbf{3 e})$ $\mathrm{R}=\mathrm{Cy}, \mathrm{R}^{\prime}=$ para $-\mathrm{C}_{6} \mathrm{H}_{4} \mathrm{NO}_{2}$ (3f) $\mathrm{R}=\mathrm{Cy}, \mathrm{R}^{\prime}=$ para $-\mathrm{C}_{6} \mathrm{H}_{4} \mathrm{OMe}(\mathbf{3 g})$ $\mathrm{R}=\mathrm{Cy}, \mathrm{R}^{\prime}=$ ortho $-\mathrm{C}_{6} \mathrm{H}_{4} \mathrm{CF}_{3}(3 \mathrm{~h})$
Scheme. 2. Isocyanate exchange to afford 2, 3a-3g

All of the compounds listed in Scheme 2 have been isolated as compositionally pure samples and characterized both spectroscopically and structurally by single crystal X-ray diffraction (see ESI for details). These studies show that such transformations are functional group tolerant and independent of the presence of electron-donating or withdrawing substituents associated with the phenyl rings. This highly modular synthesis allows access to a library of compounds with varied functional groups and potential applications in, for example, the synthesis of novel polymeric materials (through polymerization of the allyl functionalities or cross-coupling), as would be the case for $\mathbf{1 c}, \mathbf{3 b}, \mathbf{3 d}$ and $\mathbf{3 e}$. Structurally the compounds do not differ significantly from $\mathbf{1 a}$.

The ability to exchange a trapped isocyanate moiety from, for example 1a, in which PhNCO can be displaced by CyNCO to afford 2, prompted us to explore a possible mechanism for this reaction. An exchange reaction of this type is expected to be largely thermoneutral as the bonds being formed and cleaved 
are essentially identical. This was confirmed by a van't Hoff analysis of the reaction of 1a with cyclohexyl isocyanate which revealed little change to the position of the equilibrium on varying temperature (less than $4 \%$ over $50 \mathrm{~K}$ ) from which $\Delta \mathrm{H}$ and $\Delta \mathrm{S}$ values of $0.0116 \mathrm{~J} / \mathrm{mol} \cdot \mathrm{K}$ and $-0.007 \mathrm{~J} / \mathrm{mol}$, respectively, could be obtained. This energy difference was confirmed by calculations at the density functional theory (DFT) level which show that the reaction of 1a with CyNCO to afford 2 and PhNCO is thermodynamically downhill by only 2.8 $\mathrm{kJ} \mathrm{mol}^{-1}$ (within the error of the calculation). This is consistent with the experimental observation that when the reaction is carried out in a 1:1 ratio, there is equilibrium present between 1a and 2. This led us to explore the thermodynamic barrier to loss of an equivalent of PhNCO from 1a. One molecule of PhNCO and the resulting four-membered product, the intermediate invoked in Scheme 1, are $27.3 \mathrm{~kJ} \mathrm{~mol}^{-1}$ higher in energy than 1a, with a dissociation barrier of $173.1 \mathrm{~kJ} \mathrm{~mol}^{-1}$, which while high, is accessible given the experimental conditions employed to exchange isocyanates. To probe an alternative associative mechanism, MeNCO was scanned close to 1a, however a sensible bicyclic transition state could not be found, and instead only an exponential increase in energy was observed. From a purely thermodynamic perspective, a dissociative exchange of isocyanate from $\mathbf{1 a}$ is viable, which prompted us to explore the kinetics of the reaction in order to establish a reaction mechanism.

Kinetic studies were carried out on a solution of $1 \mathbf{a}$ in $d_{8-}$ toluene by addition of varying concentrations of CyNCO $(0.8,1$, $1.2,2,5$ and 10 equivalents, respectively) and the reactions monitored in by ${ }^{19} \mathrm{~F}$ NMR spectroscopy at $353 \mathrm{~K}$. Initial rate studies, in the regime where conversion to 2 is below 15\%, show virtually no change on varying the concentration of isocyante, suggesting that the process is $0^{\text {th }}$ order in isocyanate and likely to be dissociative (the reaction appears to be $1^{\text {st }}$ order in 1a until reaching equilibrium). It is worth noting that over time, the concentration of $\mathbf{2}$ present in the reaction mixtures varies with increasing concentration of CyNCO as expected, however there appears to be no significant concentration-dependence on rate.

This observation suggests that $\mathbf{1 a}$ exhibits frustrated Lewis pair like reactivity despite the fact that there is strong adduct formation between the carboborated monomer and the isocyanate. Stephan and co-workers have recently demonstrated FLP-like reactivity from a classical Lewis acidbase adduct where there is no spectroscopic evidence for a dissociative equilibrium. ${ }^{17}$

In an effort to gain further insight into the carboboration reactions which afford $\mathbf{1 a - 1 c}$, we were prompted to explore the reactivity of isocyanates towards the heavier analogues of $\mathrm{BCF}$. Interestingly, the reaction of PhNCO with $\mathrm{E}\left(\mathrm{C}_{6} \mathrm{~F}_{5}\right)_{3}$ (where $\mathrm{E}=\mathrm{Al}, \mathrm{Ga}$ ), give rise to different products that those observed with the lighter Lewis acid. The resulting products, however, strongly support an initial carboboration step in the formation of 1a-1c. As with the BCF reactions described earlier (vide supra), the initial step in the reaction of PhNCO with $\mathrm{E}\left(\mathrm{C}_{6} \mathrm{~F}_{5}\right)_{3}$ is believed to be a 1,2-carboelementation reaction in which the strongly oxophilic group 13 elements associate with the oxygen atom of the isocyanate accompanied by the formation of a $\mathrm{C}-\mathrm{C}_{6} \mathrm{~F}_{5}$ bond. In the case of $\mathrm{Al}\left(\mathrm{C}_{6} \mathrm{~F}_{5}\right)_{3}$ and $\mathrm{Ga}\left(\mathrm{C}_{6} \mathrm{~F}_{5}\right)_{3}$, the resulting imine-containing products undergo a head-to-tail dimerization to afford eight-membered ring Lewis acid-base adducts 4 and $\mathbf{5}$, even in the presence of excess isocyanate (Scheme 3). Related hydroelementation of $\mathrm{C}-\mathrm{C} \pi$-bonds has been reported by Schmidbaur and Uhl. ${ }^{18-20}$ In contrast, In $\left(\mathrm{C}_{6} \mathrm{~F}_{5}\right)_{3}$ was found to form a classical Lewis acid-base adduct in the presence of PhNCO with no evidence of carboelementation.

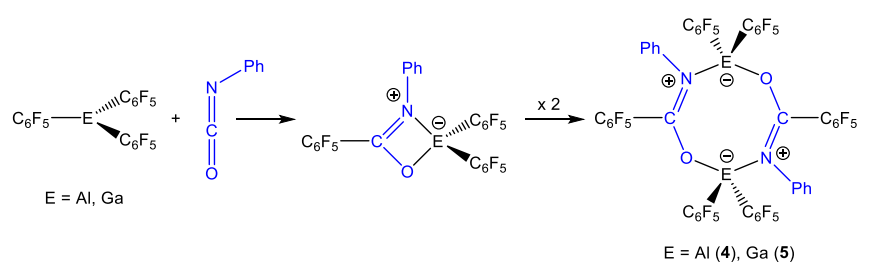

Scheme 3. Formation of 4 and 5 by carboelementation of PhNCO with $\mathrm{Al}\left(\mathrm{C}_{6} \mathrm{~F}_{5}\right)_{3}$ and $\mathrm{Ga}\left(\mathrm{C}_{6} \mathrm{~F}_{5}\right)_{3}$.

Formation of $\mathbf{4}$ and $\mathbf{5}$ is evident by the presence of two distinct environments for the pentafluorophenyl groups in the ${ }^{19} \mathrm{~F}$ NMR spectra and a single environment for the phenyl functionalities associated with the nitrogen atoms. The reaction to afford $\mathbf{4}$ is accompanied by the formation of other minor side-products and consequently only a poor quality single crystal X-ray structure could be obtained, however $\mathbf{5}$ can be isolated in moderate yields (33\%) and its structure was authenticated by single crystal X-ray diffraction.

Carboelementation reactions of this kind are of interest to synthetic chemists as they simultaneously result in $\mathrm{C}-\mathrm{C}$ and $\mathrm{C}-$ $E$ bond formation which can be further transformed. To this end, Zr-catalyzed carboalumination of alkenes and alkynes has been widely explored with trialkylaluminium reagents. ${ }^{21,22}$ Furthermore, step-wise carbogallation of alkynes upon treatment with a gallium-based Lewis acid and an intramolecular or intermolecular carbon-based nucleophile has been reported. ${ }^{22-25}$ However, the electron-withdrawing perfluoroarene substituents of $\mathrm{Al}\left(\mathrm{C}_{6} \mathrm{~F}_{5}\right)_{3}$ and $\mathrm{Ga}\left(\mathrm{C}_{6} \mathrm{~F}_{5}\right)_{3}$ allow for catalyst-free direct activation of the $\mathrm{E}-\mathrm{C}$ bonds to afford the carboaluminated and carbogallated products, respectively.

The structure of 5 (Figure 2), reveals an eight-membered cyclic core in which two imino-gallane moieties associate in a head-to-tail fashion. As with all of the carboborated products, $\mathbf{1 a}-\mathbf{1 c}, \mathbf{2}$ and $\mathbf{3 a}-\mathbf{3 h}$, the $\mathrm{C}-\mathrm{O}$ and $\mathrm{C}-\mathrm{N}$ distances of the imine are consistent with a significant degree of $\pi$-delocalisation $01-$ C1 1.282(2), C1-N1' 1.295(3) $\AA$, and exhibit comparable bond metrics to those observed in 1a, for example (C-O 1.268(2), C$N$ 1.322(2) Å). The Ga-O and Ga-N distances 1.913(2) and $1.978(2) \AA$, respectively, are in line with expected values for single bonds ( 1.87 and $1.95 \AA$, respectively). ${ }^{25}$

DFT calculations on the reaction of the postulated carboelementation intermediates with phenyl isocyanate (see ESI) reveal that in the case of boron, insertion of an additional isocyanate molecule is favoured over dimerization (by 58.5 $\mathrm{kJ} / \mathrm{mol}$ ), whereas in the case of the aluminium and gallium compounds, dimerization is favoured over isocyanate insertion (by 46.0 and $62.7 \mathrm{~kJ} / \mathrm{mol}$, respectively). This is in line with our 
experimental observation, and presumably attributable to the decreased size of boron relative to aluminium and gallium, and the increased Lewis acidity of the carboborated intermediate relative to its aluminium and gallium congeners.

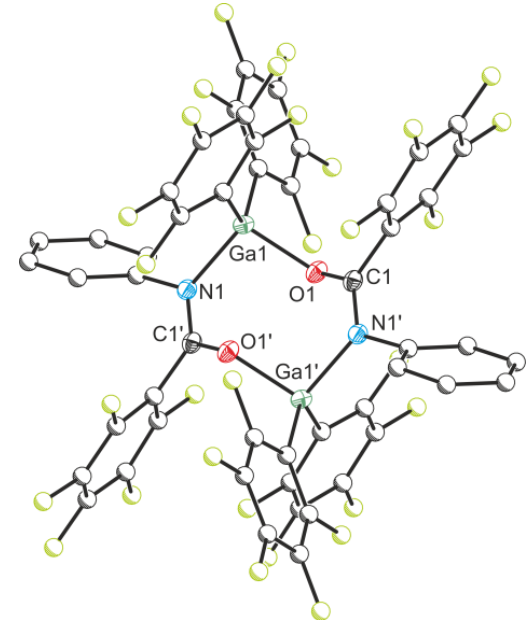

Figure 2. Molecular structure of $\mathbf{5}$. Anisotropic displacement ellipsoids set at $50 \%$ probability. Hydrogen atoms have been omitted for clarity. Atoms of the $\mathrm{Ph}$ and $\mathrm{C}_{6} \mathrm{~F}_{5}$ moieties are pictured as spheres of arbitrary radius. Selected interatomic distances $[\AA]$ and angles [']: Ga1-N1 1.978(2); Ga1-01 1.913(2), O1-C1 1.282(2), C1-N1' 1.295(3); N1-Ga1-O1 98.99(6); Ga1-O1-C1 131.54(11), O1-C1-N1' 121.28(17), C1-N1'-Ga1' 117.71(12). Symmetry operation ': $-x, 1-y,-z$

\section{Conclusions}

We have shown that tris(pentafluorophenyl)borane reacts with isocyanates to afford cyclic six-membered products resulting from the 1,2-carboboration of the isocyanate $\mathrm{C}=\mathrm{O}$ bond. The resulting products can be considered as Lewis acidbase adducts of the resulting carboboration product with an additional equivalent of isocyanate. Accordingly, such species can readily exchange the trapped isocyanate moiety via a dissociative pathway, acting as masked frustrated Lewis pairs. Carboelementation with the heavier BCF analogues $\mathrm{Al}\left(\mathrm{C}_{6} \mathrm{~F}_{5}\right)_{3}$ and $\mathrm{Ga}\left(\mathrm{C}_{6} \mathrm{~F}_{5}\right)_{3}$ is also possible, however such reactions give rise to head-to-tail Lewis acid-base adducts.

\section{Conflicts of interest}

There are no conflicts to declare.

\section{Acknowledgements}

M. M. gratefully acknowledges the Royal Society for funding (NF170051). We also thank the University of Oxford for access to Chemical Crystallography and Advanced Research Computing facilities.

\section{References}

1 (a) A. G. Massey, A. J. Park and F. G. A. Stone, Proc. Chem. Soc., 1963, 212-212. (b) A. G. Massey and A. J. Park. J. Organomet. Chem., 1964, 2, 245-250.

2 For reviews of $\mathrm{B}\left(\mathrm{C}_{6} \mathrm{~F}_{5}\right)_{3}$, see: (a) W. E. Piers and T. Chivers, Chem. Soc. Rev., 1997, 26, 345-354; (b) W. E. Piers, Adv.
Organomet. Chem., 2004, 52, 1-76; (c) G. Erker, Dalton Trans., 2005, 1883-1890; (d) D. W. Stephan and G. Erker, Angew. Chem. Int. Ed., 2010, 49, 46-76; (e) W. E. Piers, A. J. V. Marwitz and L. G. Mercier, Inorg. Chem., 2011, 50, 12252-12262; (f) R. L. Melen, Chem. Commun., 2014, 50, 1161-1174; (g) J. R. Lawson and R. L. Melen, Inorg. Chem. 2017, 56, 8627-8643.

3 (a) D. W. Stephan and G. Erker, Angew. Chem. Int. Ed., 2015, 54, 6400-6441; (b) D. W. Stephan, Science, 2016, 354, aaf7229.

4 P. Laszlo and M. Teston, J. Am. Chem. Soc., 1990, 112, 8750-8754.

5 (a) G. Kehr and G. Erker, Chem. Commun. 2012, 48, 18391850; (b) G. Kehr and G. Erker, Chem. Sci., 2016, 7, 56-65.

6 (a) B. Wrackmeyer, Coord. Chem. Rev., 1995, 145, 125-156; (b) B. Wrackmeyer, Heteroat. Chem., 2006, 17, 188-208.

7 For recent examples of metal catalyzed carboboration of alkynes see: (a) R. Alfaro, A. Parra, J. Alemán, J. L. G. Ruano and M. Tortosa, J. Am. Chem. Soc., 2012, 134, 15165-15168; (b) Y. Okuno, M. Yamashita and K. Nozaki, Angew. Chem. Int. Ed., 2011, 50, 920-923; c) M. Daini, A. Yamamoto and M. Suginome, Asian J. Chem., 2013, 2, 968-976; d) K. Nakada, M. Daini and M. Suginome, Chem. Lett., 2013, 42, 538-540; e) H. Yoshida, I. Kageyuki and K. Takaki, Org. Lett., 2013, 15, 952-955; f) Y. D. Bidal, F. Lazreg and C. S. J. Cazin, ACS Catal., 2014, 4, 1564-1569; g) M. Suginome, Chem. Rec., 2010, 10, 348-358.

8 I. A. Cade and M. J. Ingleson, Chem. Eur. J., 2014, 20, 12874-12880.

9 M. Devillard, R. Brousses, K. Miqueu, G. Bouhadir and D. A Bourissou, Angew. Chem. Int. Ed., 2015, 54, 5722-5726.

10 R. L. Melen, L. C. Wilkins, B. M. Kariuki, H. Wadepohl, L. H. Gade, A. S. K. Hashmi, D. W. Stephan and M. M. Hansmann, Organometallics, 2015, 34, 4127-4137.

11 N. J. Hill, J. A. Moore, M. Findlater and A. H. Cowley, Chem. Commun., 2005, 5462-5464.

12 M. H. Holthausen, M. Colussi and D. W. Stephan, Chem. Eur. J., 2015, 21, 2193-2199.

13 M. A. Dureen and D. W. Stephan, J. Am. Chem. Soc., 2010, 132, 13559-13568.

14 A. Stute, G. Kehr, R. Fröhlich and G. Erker, Chem. Commun., 2011, 47, 4288-4290.

15 (a) K. Huang and C. D. Martin, Inorg. Chem. 2015, 54, 1869-1875; (b) K. Huang, S. A. Couchman, D. J. D. Wilson, J. L. Dutton, and C. D. Martin, Inorg. Chem. 2015, 54, 8957-8968;

16 R. Tirfoin, J. Gilbert, M. J. Kelly and S. Aldridge, Dalton Trans., 2018, 47, 1588-1598.

17 T. C. Johnstone, G. N. J. H. Wee and D. W. Stephan, Angew. Chem. Int. Ed., 2018, 57, 5881-5884.

18 J. Ohshita and H. Schmidbaur, J. Organomet. Chem., 1993, 453, 7-12.

19 W. Uhl and M. Claesener, Inorg. Chem., 2008, 47, 4463-4470.

20 C. Appelt, H. Westenberg, F. Bertini, A. W. Ehlers, J. C. Slootweg, K. Lammertsma and W. Uhl, Angew. Chem. Int. Ed., 2011, 50, 3925-3928.

21 S. Xu and E.-i. Negishi, Acc. Chem. Res., 2016, 49, 2158-2168.

22 H. Yamamoto, K. Oshima in Main Group Metals in Organic Synthesis, Wiley-VCH, Weinheim, 2004.

23 Y. Nishimoto, H. Ueda, M. Yasuda and A. Baba, Chem. Eur. J., 2011, 17, 11135-11138.

24 I. L. Fedushkin, A. S. Nikipelov and K. A. Lyssenko, J. Am. Chem. Soc., 2010, 132, 7874-7875.

25 I. L. Fedushkin, A. S. Nikipelov, A. G. Morozov, A. A. Skatova, A. V. Cherkasov and G. A. Abakumov, Chem. Eur. J., 2012, 18, 255-266.

26 P. Pyykkö and M. Atsumi, Chem. Eur. J., 2009, 15, 186-197. 